\title{
Case study on partnering to revitalize development, delivery, and evaluation of education programs in optics and photonics for industry
}

Janice Gaines Walker, Susan Anderson, Kevin Harding, Meg Karakekes, Ray Chen

Janice M. Gaines Walker, Susan A. Anderson, Kevin G. Harding, Meg Karakekes, Ray T. Chen, "Case study on partnering to revitalize development, delivery, and evaluation of education programs in optics and photonics for industry," Proc. SPIE 3190, Fifth International Topical Meeting on Education and Training in Optics, (8 December 1997); doi: 10.1117/12.294385

Event: Fifth International Topical Meeting on Education and Training in Optics, 1997, Delft, Netherlands 
Case study on "partnering" to revitalize development, delivery and evaluation of education programs in optics and photonics for industry

Janice Gaines, Susan Anderson

SPIE--The International Society for Optical Engineering

PO Box 10, Bellingham, WA 98227-0010

Kevin Harding

Industrial Technology Institute

Sensors \& Control Systems Engineering

PO Box 1485, Ann Arbor, MI 48106-1485

Meg Karakekes

AMD and The University of Texas at Austin

Advanced Micro Devices, MS 575

5204 E Ben White Blvd, Austin, TX 78741-7306

Ray Chen

The University of Texas at Austin

Microelectronics Research Ctr

PRC-MER 1.606/R9900 E\&CE Dept.

Austin, TX 78758

\begin{abstract}
For the past three years, the National Alliance for Photonics Education in Manufacturing (NAPEM) has "partnered" with industry to develop, deliver and evaluate continuing education programs on optics and photonics applied to manufacturing processes. NAPEM is an alliance of CREOL/University of Central Florida, the Industrial Technology Institute, the University of Connecticut, The University of Texas at Austin, and SPIE--The International Society for Optical Engineering. NAPEM formed in 1994 as the result of partial funding through a U.S. Technology Reinvestment Project/Manufacturing Education and Training grant monitored by the National Science Foundation. NAPEM targeted four applications of optics in manufacturing processes. Each of these manufacturing process corresponds to a geographical region in the United States: semiconductor manufacturing in the Southwest, durable goods manufacturing in the Midwest, laser materials processing in the North East, and optics manufacturing in the South East. Course programs were typically modular, offered in half- to full-day formats.

This paper focuses on lessons learned by Alliance members in the process of fulfilling NAPEM's mission. Specifically this paper will address:

- challenges and benefits of university and professional association partnerships on program development, promotion and evaluation;

- $\quad$ challenges and benefits of partnering with industry on program development, evaluation and continuation;

- the importance of developing "learning partnerships" with human resources, engineering and technical managers from industry;

- $\quad$ matching delivery mechanisms to industries' educational "habits;"

- challenges and solutions for addressing different industries' readiness to utilize high-technology.
\end{abstract}

Keywords: optics education, photonics education, optics manufacturing, semiconductor manufacturing, laser materials processing, durable goods manufacturing, continuing education, learning partnerships, Technology Reinvestment Project 


\section{INTRODUCTION}

The NAPEM experience started as an experiment in response to a U.S. Government initiative, and resulted in a wealth of critical partnerships formed between Alliance members and industry which. These partnerships now position NAPEM members to meet a number of evolving continuing technical education demands.

This process began with the Technology Reinvestment Project (TRP) which was launched by the U.S. Government in 1993 as a response to the upheaval caused by the end of the Cold War. The goal for TRP was to fund programs and partnerships that would "promote and develop national industrial capabilities that provide the most advanced and affordable military systems and the most globally competitive commercial products." 1 At the same time, the US aerospace industry was collapsing and, as a result, many traditional education providers, including SPIE, were struggling to maintain financially viable programs. Additionally, due to the rate of technological advancement, many other industries were struggling to keep up. Rapid growth in chip manufacturing, and revolutionized processes in durable goods manufacturing, gave rise to many companies being faced with finding training and education on non-traditional technical subjects with drastically different applications orientations...in real time. Finally, the pool of skilled engineering graduates and post-graduates available for employment was diminishing due to changes in demographics and national education interests. As a result, the days of mass attendance to courses critical to the aerospace industry were over, and a demand from quality-minded companies for "proof"of return on training investment and technical skills updating began. In essence, U.S. industry and numerous educational institutions were in need of a paradigm shift to keep pace. TRP was there to help.

The funding by TRP provided NAPEM members with the incentive and financial support to significantly alter the way they approached identifying, developing and providing continuing education (as well as accredited programs) to serve their region's needs. Thirty-six months after grants were awarded in 1994, TRP funding has ended and NAPEM programs are transitioning to self-sufficiency. These programs, with genesis in NAPEM, continue based on successful needs assessments and strong partnerships reinforced by clear demonstrations of return on investment, and a solid foundation of knowledge realized by companies who employed NAPEM programs.

\section{BODY}

The NAPEM approach and structure, "emphasized partnering in curriculum development, program design, and outreach to multiple potential audiences." ${ }^{2}$. For each program, partnerships existed on a three-way basis among Alliance members: industry, educational institutions and SPIE. Each partner brought specific strengths. Strong communication and the combined knowledge and expertise of the three partnering organizations was crucial to the success of each program.

Figure 1.

Management Structure of NAPEM - The National Alliance for Photonics Education in Manufacturing

NAPEM

Management

Structure

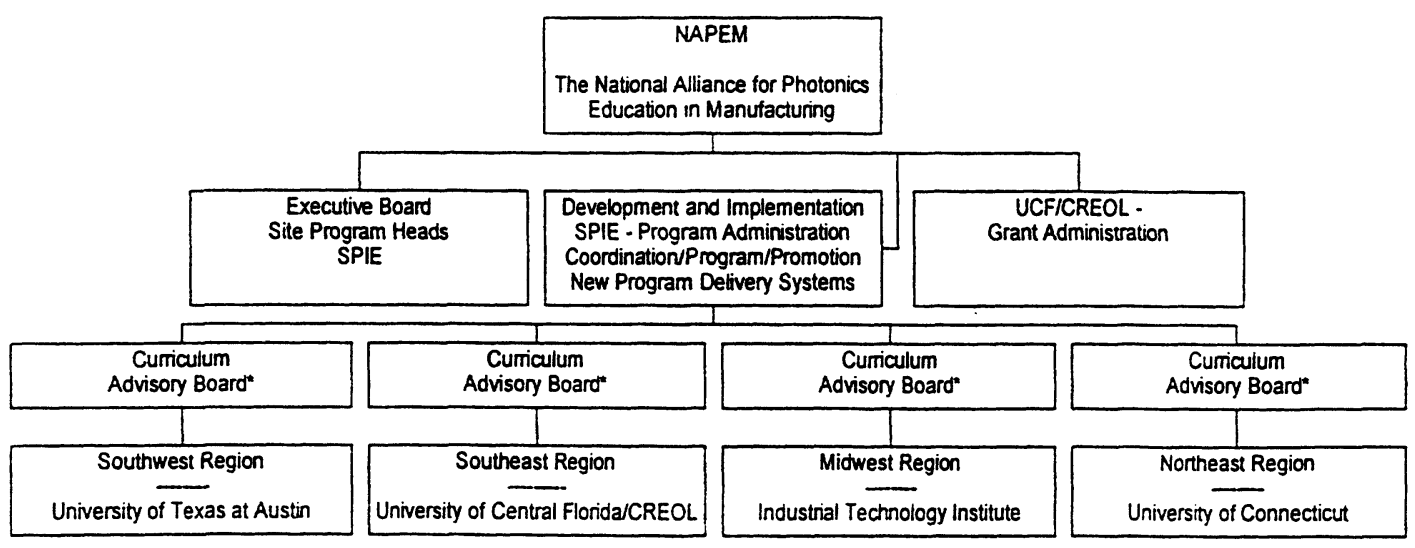

*Industry representatives, Alliance member PIs, Key staff and faculty 


\section{Figure 2. Partnership Model}

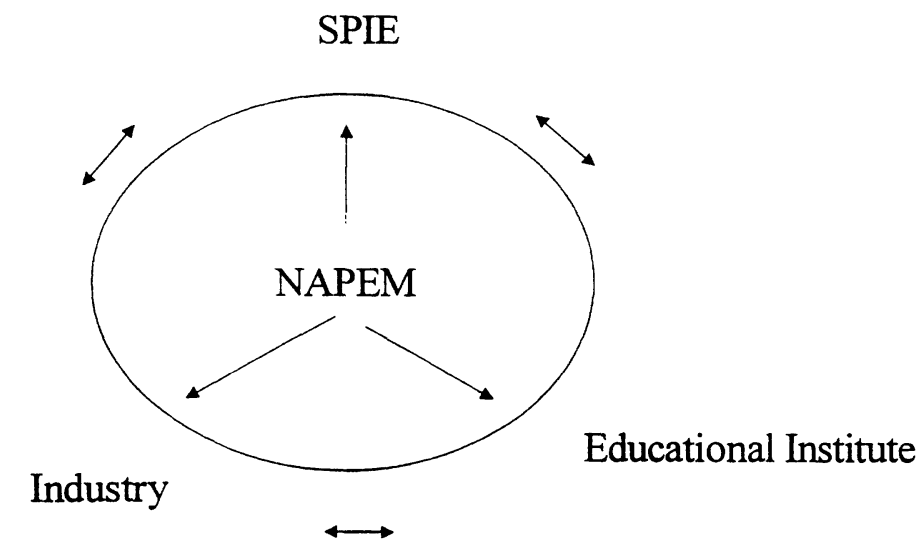

\subsection{Challenges and benefits of university and professional association partnerships on program development,}

promotion and evaluation

\section{Partnering in the Initial Phases}

The beginning phases of NAPEM involved an essential society/educational institution partnership. The TRP program required that a university serve as the grant contractor with the U.S. government. The Society played a key role in bringing together input from SPIE's leadership and staff in conceptualizing the project, and in coordinating the proposal writing among the five Alliance members.

\section{Partnering in the Program Phase}

On an ongoing individual program basis, the educational institutions served to establish "regional program credibility." Each university enjoyed previously established formal, ongoing relationships with specific companies in their region which, for example on a formal basis, provided for equipment grants in exchange for research performed by the university, or more informally served the individual educational needs of regional company employees. Additionally, in the program development phase, the educational institutions provided curriculum expertise through the participation of their faculty in developing or teaching NAPEM courses.

SPIE's role during the Program Phase was to provide:

- $\quad$ expertise on designing and structuring the courses for a continuing education format;

- $\quad$ technical curriculum "drafts" for use in initial program development work;

- a large instructor database from which to draw including industry, government and academia experts;

- internationally recognized Continuing Education Units (CEUs);

- promotional expertise and capability through identification of mailing lists, development of promotional materials,

- the practice of performing "outreach" or holding meetings with industry department managers and training and human resources representatives to "sell" the program once developed.

Through working with SPIE in this area, the educational institutions learned how outreach can facilitate promoting courses (and eventually lead to developing a partnership with industry representatives (see section 2.3)).

\section{Evaluation}

The partnership between The University of Texas at Austin (UT) and SPIE was the main impetus behind the evaluation process which was developed for the entire NAPEM program. This process began with a Level 1 Evaluation (Participant Satisfaction measured at the time of the course), using SPIE's modified course evaluation form (Figure 3). This form was used to collect customer satisfaction input on the course content and instructor, to gather suggestions for future course topics, and gather participant profile data.

Additionally, Level 3 Evaluation (Application of Learning) was instituted. The Level 3 Evaluation process involved 
following up with participants at 3-to 6-month intervals to determine how, and if, participants applied the information they learned to their work process. This information was collected and provided back to training and engineering managers following the completion of the course program. Additionally, it was revisited at the time the following year's program was being developed. This later aspect was key to the development of the industry-NAPEM learning partnership (see section 2.2). Significant application of course materials by NAPEM course participants from any given company typically resulted in an increased interest in participation by their company the following year.

\subsection{Challenges and benefits of partnering with industry on program development, evaluation and continuation}

\section{Industrv: an Over-Solicited Stakeholder}

From the start, NAPEM planned to involve industry. Partnering with industry was integral to supporting NAPEM's mission of ". . enhancing the national manufacturing training effort by providing regionally-based educational programs focusing on applying photonics in commercial applications." During the grant proposal stage, NAPEM allocated resources to solicit industry involvement on how to apply technical continuing education to improve their processes. Developing these solicitations into partnerships proved to be a significant challenge.

Four aspects contributed to the difficulties in "learning partnership" formation which still hold true today:

- Every week. for-profit and not-for-profit organizations offering engineering learning opportunities vie for industry representatives' attention, input and dollars.

- Industry representatives must "make" time to review literature, assess needs, prepare for advisory meetings, and introduce educational opportunities to engineers.

- A very few industry representatives also evaluate the value of education or the return on investment (ROI) of their training expenditure..

- Engineering continuing education providers often overlook that fact that there can be two or more different industry stakeholders: the engineering manager and the technical training specialist. One or both functions may know the engineering learning needs, control the purse strings, and endorse learning opportunities.

Finally, engineering managers do the above tasks in addition to their "real" jobs. There are far more startup programs, focus groups, advisory councils, and training courses out there than industry stakeholders can attend to.

\section{Moving From Vendor to Partner}

As NAPEM representatives approached industry stakeholders, it became clear that industry representatives lumped NAPEM into one of two broad categories: Vendor or Potential (Learning) Partner. The paradigm from which industry viewed NAPEM set the tone for future interactions. Table 1 illustrates how each paradigm influenced industry representatives' responses. 
Table 1 : Industry Response to Events Based on Paradigm

\begin{tabular}{|l|l|l|}
\hline Event & Vendor Paradigm & Partner Paradigm \\
\hline Response to a phone call & What you are selling? & $\begin{array}{l}\text { How can we work together to meet my } \\
\text { engineers' learning needs and therefore } \\
\text { my company's business goals? }\end{array}$ \\
\hline $\begin{array}{l}\text { Reaction to a packet of } \\
\text { info or e-mail }\end{array}$ & More materials I don't have time to read. & $\begin{array}{l}\text { Great, the information I've been } \\
\text { expecting. I'll read it. }\end{array}$ \\
\hline $\begin{array}{l}\text { Reply to the } \\
\text { opportunity to have } \\
\text { NAPEM reps visit }\end{array}$ & $\begin{array}{l}\text { Are these "university types" selling a } \\
\text { class taught by someone out of touch with } \\
\text { industry? Should I agree to meet? }\end{array}$ & $\begin{array}{l}\text { NAPEM helps keep engineers up-to-date } \\
\text { \& contributes to my organization's ability } \\
\text { to compete. }\end{array}$ \\
\hline Attitude at a meeting & $\begin{array}{l}\text { Sell me on your ideas. I've done my part } \\
\text { by showing up. }\end{array}$ & $\begin{array}{l}\text { I am ready to discuss program ideas and } \\
\text { my engineers' learning needs. }\end{array}$ \\
\hline $\begin{array}{l}\text { Response to follow-up } \\
\text { communication }\end{array}$ & $\begin{array}{l}\text { Does not respond to repeat phone calls or } \\
\text { e-mails. }\end{array}$ & $\begin{array}{l}\text { Responds to communication. Sometimes } \\
\text { initiates. }\end{array}$ \\
\hline $\begin{array}{l}\text { Involvement with the } \\
\text { course delivery and } \\
\text { evaluation process }\end{array}$ & Signs authorization for payment. & $\begin{array}{l}\text { Gets the "right" engineers into courses. } \\
\text { Talks with managers \& participants } \\
\text { before and after -- interested in learning } \\
\text { transfer. }\end{array}$ \\
\hline
\end{tabular}

At the close of the NAPEM program, the Partner Paradigm, as shown above, had been realized with most programs.

\section{Program and Partnership Development Phase}

The companies that readily viewed NAPEM as a potential partner either had previous positive experience with a NAPEM member organizations e.g., SPIE or a specific university, or the companies had positive regard for an individual staff or board member associated with NAPEM. These "friendly" companies would attend bi-annual curriculum advisory board meetings and would welcome NAPEM "staff" to their sites for various curriculum development and related discussions. For example, the Technical Training Manager at one organization had such positive regard for two individuals associated with NAPEM that he arranged for a multi-company meeting during which NAPEM representatives could explain their mission and desire for partnering. During this meeting, an industry representative pointed out that the instructor biographies stressed each instructor's academic qualifications. He clarified that professional engineers wouid be equally (or more) interested in each instructor's industry accomplishments--valuable feedback for NAPEM.

NAPEM quickly learned that company visits, or "virtual curriculum advisory board meetings," were much more effective than the bi-annual curriculum advisory board meetings originally conceptualized in the grant proposal. These initial meetings were held at NAPEM member site and brought in members from various companies and organizations. NAPEM learned that more industry input was gained by visiting individual companies such as articulated specific learning needs or named preferred instructors. In one instance, two companies pulled together a cross section of engineering managers and technical training staff for a focus group meeting with NAPEM staff. More often in these meetings, industry representatives identified what did NOT meet their needs. For example, NAPEM learned that originally proposed weeklong courses took engineers away from the workplace for too long; shorter courses were more desirable. In another instance, one company thought highly of a specific instructor for the topic of Lithography for Manufacturing so this instructor was recruited.

Most often industry representatives wanted to see samples of course descriptions and available instructors. From these, they identified what met or did not meet their needs. One company even asked to see the courses taught two years earlier; this company felt behind the technology curve and was certain that less than up-to-date courses would be the place to start with their out-of-date engineers. 
Persistence was a key to forming and maintaining many NAPEM partmerships. Even with up-front "industry buy-in" to the partnership process, in nearly twenty-five percent of the cases in which industry representatives agreed to meet with NAPEM representatives, the meetings went awry. In these instances either the industry representative would not be available at the agreed upon time, would not have prepared for the meeting, or would not be a person with authority to act on behalf of the company. NAPEM representatives flew to cities for meetings with industry representatives who did not show up at the meeting, despite the fact that the industry contact selected the meeting date and time, received a written confirmation, and was left a phone message reminder the day before the meeting. Management turnover in industry also resulted in challenges to maintaining productive contacts within companies, and dedication on the part of NAPEM representatives was required to ensure continuation of the partnership. On one occasion NAPEM representatives even braved rattlesnake infested parking lots in order to meet the third new representative for a company in a one year time span!

Sometimes this persistence directly influenced turning a vendor paradigm into a partner paradigm. In the example cited above, the third industry representative for a major manufacturer was impressed that NAPEM had been in contact with both her successors and that her company had participated in NAPEM courses the previous year. Other times, flexibility and the acknowledgment that "the customer is always right" were key to the paradigm shift. On one occasion, NAPEM staff traveled 85 miles in a torrential downpour to meet with industry representatives. Although the NAPEM staff was on time, the industry representatives were running two hours behind schedule. The industry representatives offered two alternatives, 1) delay the meeting until after the close of the business day or 2) cancel the meeting. The NAPEM staff agreed to wait and when the meeting commenced the industry representatives. though tired from a long day, saw how what NAPEM offered would benefit their engineers. This company has become a NAPEM partner and sent 26 employees to attend NAPEM courses.

Another example of persistence came from NAPEM's outreach to Lockheed during its plant shutdown in Austin, Texas. After a year of repeatedly referring NAPEM information to the outplacement agency, Lockheed representatives agreed to meet with NAPEM. As a result of this meeting, NAPEM was instrumental in offering re-training to displaced Lockheed employees.

\section{Solidifying the Partnership}

The relationship between NAPEM and its industry partners was complex. It was cemented by more than an industry desire for continuing engineering education and the providing of that education. The technical training staff at partner companies expected NAPEM to help forecast training needs and meet them. The engineering managers wanted not only quality courses but also participant manuals or course notes that were excellent reference material. Both the engineering managers and technical training staff at partner companies also wanted help justifying the cost of the courses.

While NAPEM did not have access to confidential financial data from any industry partner, NAPEM followed up with participants to see if and how course attendees transferred learning from the courses to the workplace (Level 3 Evaluation). Thus, for specific courses, NAPEM could tell an industry partner or prospective partner ways in which past course attendees transferred information to the workplace and how it benefitted the sponsoring company. (NAPEM could also identify the occasional poor course and cancel it or work with the industry expert and instructor to improve the course.) The industry partners could then justify support for engineering continuing education because a certain course enabled a company to revolutionize a certain procedure, an engineer to generate a patentable idea, a technologist to select a superior tool, or a design engineer to more effectively interface with manufacturing.

Industry wants and in some instances requires this kind of data regarding the value of education. Engineering managers and technical training specialists appreciated NAPEM's ability to supply data that enabled the industry partner to justify the resource costs for training. NAPEM staff felt this aspect truly solidified the partnership as one of "learning" as it completed the entire process loop by providing the feedback upon which to assess value and implement modification for the next program. 
Partnering Across Industrv

Further, by involving companies across an industry in the needs assessment, course development, program deployment, and evaluation phases of these NAPEM educational programs, all industry partners shared the cost of the development and reaped the benefit of a high quality educational experience. On average, $50 \%$ of NAPEM course attendees came from industry partners. One partner is responsible for over 150 NAPEM course registrations annually.

\subsection{The importance of developing "learning partnerships" with human resources, engineering and technical managers from industry}

Typical constraints faced by external continuing education providers include minimal contact with the learner before the learning event, no formal authority by the company contact to support transfer of learning to the workplace, and limited post-course access to the learner and/or learning transfer data. Through the process of partnering with industry, NAPEM gained access to internal training proponents and learners, and was able to show industry the value to sending their employees to NAPEM courses. Thus the value of strong industry partnerships became clear: by working in tandem with industry, NAPEM provided cutting edge courses and could "prove" they met industry's needs.

\section{Within Companies}

Involving multiple training "champions" from each company in the partnership was essential to ensuring the partnership's success. NAPEM found that including human resources, engineering and technical managers in the beginning stages of the partnership was a benefit to the company as well as to NAPEM. Drawing on each area of expertise the organization was able to better assess their engineers' technical continuing education needs, discuss the financial aspects of implementing the attendance, and were then able to participate in the evaluation process more effectively. NAPEM assisted (or in some cases instigated) the communication processes across departmental lines within organizations through focus groups and curriculum advisory meetings held at company sites. As the course program progressed, the interaction between the human resource and technical people within organizations was sometimes improved and positively commented upon. The technical staff in organizations appreciated the efforts on behalf of the human resource personnel to work with NAPEM in providing their engineers the courses they needed.

\section{The Importance of Third-Level Evaluations to the Partnership}

As mentioned above, the Level 3 Evaluation aspect of NAPEM programs was what truly solidified the "learning" aspect of the partnership. But, conducting evaluation to determine if and how learning is transferred to the workplace is difficult. Feedback can be subjective and getting people to respond is resource intensive. Timing of the evaluation can produce varying results depending on when the learning transfer occurred or was applied. But in the end, the evaluation feedback was extremely valuable to NAPEM in maintaining the partnership and also in providing real data upon which to base the success of the relationship.

A model which describes the learning transfer aspect of the partnership activity to the workplace is a follows:

Table 2. Learning Transfer Partnership Model ${ }^{4}$

\begin{tabular}{|c|c|c|c|}
\hline & $\begin{array}{c}\text { Before: } \\
\text { Program Development } \\
\end{array}$ & $\begin{array}{c}\text { During: } \\
\text { At the Course Program }\end{array}$ & $\begin{array}{c}\text { After: } \\
\text { Transfer to Workplace }\end{array}$ \\
\hline NAPEM & $\begin{array}{l}\text { - Assess training needs } \\
\text { - Recruit instructors }\end{array}$ & $\begin{array}{l}\text { - Ask learners to consider how } \\
\text { new knowledge will be applied at } \\
\text { workplace }\end{array}$ & $\begin{array}{l}\text { - Ask participants how learning was } \\
\text { applied at workplace } \\
\text { - Share data with training managers }\end{array}$ \\
\hline $\begin{array}{l}\text { Industry } \\
\text { Partners }\end{array}$ & $\begin{array}{l}\text { - Suggest course topics } \\
\text { - Sponsor attendees } \\
\text { - Budget approval }\end{array}$ & $\begin{array}{l}\text { - Visit program site } \\
\text { - Take courses }\end{array}$ & $\begin{array}{l}\text { - Ask for a report from attendees } \\
\text { - Support an internal "mini class" to } \\
\text { non-participants } \\
\text { - Encourage employee experimentation }\end{array}$ \\
\hline
\end{tabular}


Some of the ways NAPEM participants reported using course information in the workplace were as follows:

- $\quad$ modifying equipment
- $\quad$ more effectively interacting with customers
- $\quad$ teaching the information to others
sharing course information with others ( $55 \%$ of respondents reported this).

Sample quotes which were conveyed back to training or engineering managers by NAPEM included:

"I plan to incorporate some of the ideas into the etch course I teach to engineers."

-a senior engineer

"It helped me with a particle monitoring system project. I will continue to use the course notes as reference material."

--an entry level engineer

"Despite the fact that I will not directly apply the information learned in this short course to my current work, I found the course very informative and worth the time and money invested. Perhaps the most important message carried from the class was the changes in processes and equipment that will be required in the future." --an engineering manager

Maintaining the "virtual curriculum advisory board" of managers and human resource personnel which received this feedback and incorporated it into future programs required extra effort for NAPEM. The effort was ultimately very worthwhile in achieving the partners mutual goals.

\subsection{Matching delivery mechanism to industry's educational "habits"}

Each industry NAPEM worked with had specific needs related to program timing, format, cost, location and topical orientation. Only as the partnerships between NAPEM and industry matured were these "habits" more fully understood and addressed.

The durable goods industries are unique. The courses NAPEM offered these "rustbelt" industries required different tactics than the other, higher tech, regional programs. The durable goods manufacturing industries are so diverse in nature that each process including forming, fabricating, and assembly tends to stand as industry sectors unto themselves. A common "habit" in all these industries is to focus on immediate solutions to immediate problems. This often means that the solution is sought at trade shows or "hot topic" workshops or courses when the need arises. For example, at one trade show in the robotics and machine vision industry, a full 80 percent of tutorial/course attendees sign up at the show. This suggests that there is not an opportunity to plan very far ahead for these types of events. If a sudden problem arises in the plant, a current problem becomes solved and suddenly the worker is either unavailable or uninterested in attending a tutorial on a specific topic. This same schedule limitation for training makes long time commitments often unworkable. Even a day or so away from production may be too much. Production problems need to be addressed immediately or the company loses large amounts of money. This habit suggested to NAPEM that the use of trade show events, and regularly repeated events, offered the best chance to address this sector. NAPEM proceeded with this programming format in serving the durable goods manufacturing area.

\section{Distance Education}

Through the course of interacting with industry, NAPEM determined that one high tech industry (semiconductor manufacturing) regularly utilized live satellite and videotape delivery means for accessing continuing education. As a result, NAPEM developed and delivered one course over these two delivery means. Companies accessed the live broadcast of the course via the National Technological University (NTU) network, or could purchase the resulting 5-hour video and course notes for in-company training. 


\subsection{Challenges and solutions for addressing different industries' readiness to utilize high-technology}

One of the key elements the TRP competition emphasized to qualify for funding was that of developing programs that "promote and develop national industrial capabilities that provide the most advanced and affordable military systems and the most globally competitive commercial products." In order to meet this criteria, one area NAPEM targeted was that of applying high technology solutions (optics/photonics technology capabilities) to durable goods manufacturing processes.

The partnering process in this area was crucial to developing an understanding of the durable goods industry's current level of understanding and use of apply enabling technologies such as optics and photonics in their processes. The discussion below suggests an important delineation of educational or training activities directed at the manufacturing sector that was realized by NAPEM through this process. For both the promoter and user of a new technology, the training must develop a degree of confidence that the technology can get the job done. Neither user or technologist needs in-depth training on the technology, but they both need training on how to use the technology. Compartmentalization of manufacturing operations suggests an application-specific approach to the educational process. Major areas such as assembly, fabrication, and forming constitute the entry point to bring application knowledge, as the first step to acceptance of a new technological tool.

\section{The Challenge of Bringing High Tech to Durable Goods Manufacturing}

NAPEM found that for an educational mechanism to be effective it requires both appropriate communication tools as well as good reception by the participant. Traditional large volume manufacturing such as seen in automotive or furniture sectors is based upon long established methods coupled to high capital investment in machinery. The retooling of a production plant can take one to two years to complete, resulting in a facility with an expected life cycle of five to eight years. There have certainly been strides made over the past several years to accommodate flexible or agile manufacturing practice, but even these assume a fixed type and level of technology. For this reason alone, the time to introduce a new technology of any real significance to the manufacturing process is typically seven to ten years.

NAPEM learned that the basis from which acceptance of new technology comes is education. The maker of a new technology tool well understands the pros and cons of the technology. To the industry user who well understands the process, the technology tool begins as a form of magic. Neither side really does, or ever will truly understand the other's point of view. But, when the purveyor of the technology understands enough of the application to know what will not work, and the user understands enough of the technology tool to understand what will work, a mutual confidence can be achieved. By this logic, the target of the educational methods as applied to industry must be a two sided communication process so as to achieve the middle ground of understanding. NAPEM addressed this by working with industry floor managers and industry association representatives to determine the best way to communicate and build this confidence with both the education 'buyer' as part of the NAPEM partnership, as well as the engineers who would take the courses.

For industry people to accept a new technology tool they must understand what it will do for them, as well as what it will not do. A person working in metal forming needs to see how the technology is used in the metal forming operation, while a person working in casting must understand the technology from the casting perspective. Neither worker wants or needs to become an expert in this new technology, nor do they have the time or motivation. It is difficult enough to understand the nuances of such a manufacturing process without needing to know all the fine detail of the associated technologies from power generation to shipping practices. You do not need to know how to build a car to apply it to the road. Therefore, acceptance or "confidence" in a new technology tool becomes focused on "driver training," that is the application issues and operational aspects of the tool. The training and education that needs to take place is thereby equally as focused on solutions to specific application problems. As a consequence of coming to this realization in working with this industry, NAPEM took a "solutions" approach in their promotions and partnering discussions, and to the way they organized their courses. 


\section{OBSERVATIONS AND RECOMMENDATIONS}

The Critical Three-Wav "Learning Partnership"

Although SPIE's history and reputation of performing customer outreach to promote educational programs was new to other NAPEM members, what evolved in authoring the proposal was the even more unique concept which NAPEM embodied of including the voice of the industry customer in the curriculum development process, and in the Level 3 Evaluation feedback. As NAPEM activities evolved, this aspect grew in importance and scope and became referenced as the "learning partnership." the process of which is described in Table 1, Section 2.3. The learning partnership is probably the most significant outcome of the entire NAPEM activity, and one that will continue to be developed and maintained by SPIE and other (now former) Alliance members.

A key lesson learned in the process of forming these learning partnerships is that they take significant time to nurture and develop. The fast pace of industry, the distributed responsibility for educational activities within an organizations, and the rate of management turn over all contribute to the challenge of developing and maintaining the partnership.

Program results

In the end NAPEM realized enough growth to sustain some regional programs without grant support.

Table 3. Results of NAPEM Programs

\begin{tabular}{|l|l|l|l|l|}
\hline & $1994^{*}$ & 1995 & 1996 & $1997^{*}$ \\
\hline Overall program evaluation rating & 4.11 & 4.19 & 4.11 & 4.40 \\
\hline Course Registrations & 227 & 741 & 644 & 129 \\
\hline
\end{tabular}

*Partial year.

Fluctuations in program rating and attendance shown in Table 3 are due to significant changes in course format or the number of courses offered in any given year. For example, in 1996 hands-on courses were developed for the Connecticut and Texas programs, which were a new format and experience for NAPEM members. Also, 1994 and 1996 reflect only several months of activity rather than an entire year's worth.

Major companies listed below participated in NAPEM by sending groups of engineers or giving curriculum input to the course programs:

3M - Advanced Micro Devices - Hughes Danbury - Lockheed Martin - Sony - SEMATECH - Texas Instruments VLSI Technology Inc. - Westinghouse

\section{SUMMARY}

It is our observation that the success of NAPEM is rooted in the partnerships that were formed in the process of developing, delivering and evaluating course programs. Through partnering, NAPEM learned numerous critical factors:

- How to utilize each partners' strengths, identify challenges or weaknesses in the partnership, and to be flexible and develop solutions that work for the partnership.

- The importance of researching, understanding and accommodating the daily and institutional challenges industry partners face in their ability to work in a partnership and in filling their continuing education needs.

- The benefit of partnering with organizations who are known and have a positive track record with potential industry customers.

- The positive outcome of fostering partnering of engineers. training, and human resource people within their own organization to instigate or enhance development of engineering continuing education activities.

- That follow-up evaluation and feedback is critical to the success of all partners - the learner, the organization, and the training provider. It provides a way to measure return on investment and a wealth of information and basis for 


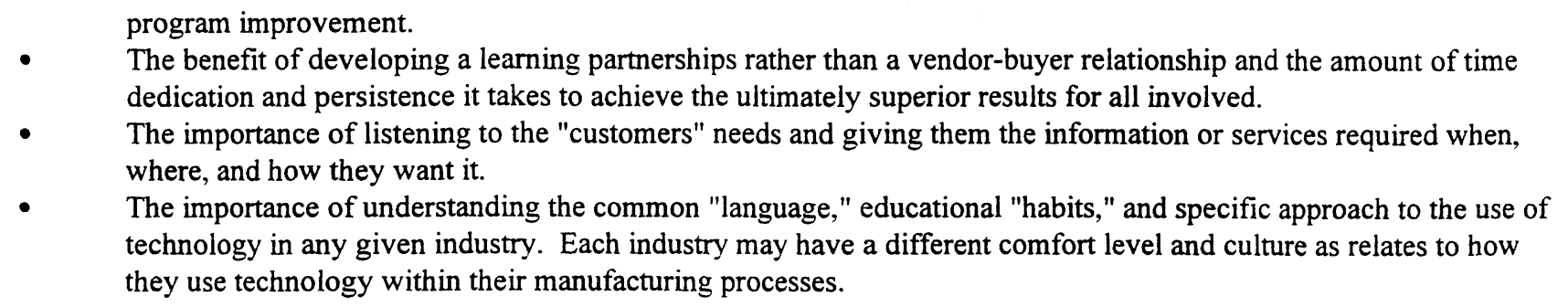

\section{The Future}

NAPEM's role is essentially concluded for the purposes of the grant funding cycle and project requirements, however, many of the programs and relationships developed under its auspices will be continued. For example, building on NAPEM experience, SPIE has launched a new activity known as "In-Company Programs" which provides customized technical courses at the corporate site, and regional course programs in specific technology "centers" to continue serving the established needs of NAPEM-formed partnerships. Additionally, SPIE will analyze the NAPEM model for its application to international programs.

ITI continues to host "solutions" courses at regional trade shows to serve the durable-goods manufacturing industry. The University of Connecticut continues to work with its list of industry partners developed under NAPEM to provide continuing education programs in laser materials processing in a hands-on format on-campus or via video-conferencing technology. CREOL works closely with Orlando companies to develop pertinent optics manufacturing courses. And finally, The University of Texas at Austin continues to work closely with regional companies to provided accredited programs pertinent to the semiconductor manufacturing industry.

All NAPEM members continue to employ the partnership model learned and developed through this project.

\section{ACKNOWLEDGMENTS}

The authors wish to thank the following people and organizations associated with the success of this project: Ted Saito and David Casasent, SPIE leadership 1994-95; Terry Montonye, Scott Walker, Jim Pearson, Jit Rai-Choudhuri, Elsie Heinrick, Sharon Kirkpatrick, Kathleen Robinson, Kristi Bell, SPIE staff; Doug Holmstrom, Rick Feinberg, Consultants; M.J. Soileau, Jin Kim, Jim Moharam, Donna Wilson, Thomas O'Neal. CREOL/Univ. of Central Florida; Janna Oddie and Teresa Perry, Univ. of Texas at Austin; Ray Vanderbok, Industrial Technology Institute; Chandra Roychoudhuri, Tariq Mazur, Richard Becherer, Univ. of Connecticut; Al Harvey, Deborah Crawford, National Science Foundation; United States Government.

\section{FOOTNOTES/REFERENCES}

I"Program Information Packet for Defense Technology Conversion, Reinvestment and Transition Assistance," ARPA, Technology Reinvestment Project, Arlington, VA. March 10, 1995.

${ }^{2}$ NAPEM Executive Summary, 3 Nov. 1994, p. 3.

${ }^{3}$ S.A. Anderson and J.M. Gaines, "The National Alliance for Photonics Education in Manufacturing: training in the application of photonics to enhance national manufacturing." 1995 International Conference on Education in Optics. M. J. Soileau. Proceedings of SPIE vol. 2525, paper no. 93, pp. 664-675. SPIE, Bellingham, WA, 1995.

${ }^{4}$ S.A. Anderson and J.M. Gaines, "NAPEM-National Alliance for Photonics Education in Manufacturing: partnering with industry to re-engineer photonics education programs to enhance manufacturing processes." TRP/MET Grantee Meeting, Arlington, VA, April, 1997. 
S.A. Anderson and M. Karakekes. "Assessing the Value of Professional Development Workshops." Performance Measurements for Training Conference, Atlanta. GA, May 1997.

M. Karakekes and R. Chen, "Pioneering a learning partnership: The University of Texas, SPIE and the Federal Government together extend a hand to semiconductor manufacturers." Proceedings of SPIE 1995 International Conference on

Education in Optics. M.J. Soileau. Proceedings of SPIE vol. 2525, paper no. 42, pp. 608-617. SPIE, Bellingham. WA, 1995.

M. Karakekes. "An Experimental Partnership: Addressing Diverse Needs." Chapter in Transferring Learning to the Workplace ,edited by Mary Broad. American Society for Training and Development, Alexandria, VA, 1997. 